\title{
Comparison of modified total leaflet preservation, posterior leaflet preservation, and no leaflet preservation techniques in mitral valve replacement - a retrospective study
}

\author{
Yilong Guo* ${ }^{*}$, Shuwu He, Tianguang Wang, Zelun Chen and Yue Shu
}

\begin{abstract}
Background: Mitral valve replacement with the total leaflet preservation technique can yield good results; however, its development is limited by patient-valve mismatch. Therefore, we compared the efficacies of the modified total leaflet preservation technique, posterior leaflet preservation technique, and no leaflet preservation technique in mitral valve replacement.
\end{abstract}

Methods: Clinical records and echocardiographic data of 180 patients who underwent mitral valve replacement for rheumatic mitral valve disease between 2009 and 2017 were analysed retrospectively to summarise the operative experience and short-term (six months) results. The patients were divided into three groups: group A ( $n=62)$, treated with the modified total leaflet preservation technique; group $B(n=80)$, treated with the posterior leaflet preservation technique; and group C $(n=38)$, treated with the no leaflet preservation technique.

Results: No significant difference in the preoperative clinical data was noted between the groups $(p>0.05)$. The clamp and recovery times of group A were longer $(p<0.05)$ and shorter $(p<0.05)$, respectively, than those of groups B and C. The postoperative left ventricular end-diastolic diameter, left ventricular end-systolic diameter, and left ventricular ejection fraction of group A were significantly better than those of groups B and $C$. The incidence of low cardiac output syndrome in group A was lower than that in group $C(p<0.05)$. There was no postoperative left ventricular posterior wall rupture or mechanical valve dysfunction in group $A$.

Conclusions: The short-term results of the modified total leaflet preservation technique were better than those of the other techniques. This technique is also suitable for patients with rheumatic mitral valve stenosis.

Keywords: Mitral valve, Operative procedures, Heart valves

\section{Background}

Mitral valve replacement (MVR) - an important treatment for rheumatic mitral valve disease-has been widely promoted and rapidly developed worldwide. Various MVR techniques have emerged. In 1964, Lillehei et al. found that the mortality and complications were lower, and the cardiac function was better if some part of the mitral valve was preserved through MVR [1]. Therefore, studies on valve preservation techniques have increased since then. Although Alsaddique proved that MVR with total leaflet preservation technique can achieve better results [2], its development has been limited by patient-valve mismatch. Therefore, we developed a modified version of this technique and compared its efficacy with that of the posterior leaflet preservation and no preservation techniques.

\footnotetext{
* Correspondence: 847287951@qq.com

Department of Cardiovascular Surgery, The Second Affiliated Hospital of

Hainan Medical University, 48th of Bai Shui Tang Road, Haikou, Hainan

570311, People's Republic of China
}

(c) The Author(s). 2019 Open Access This article is distributed under the terms of the Creative Commons Attribution 4.0 International License (http://creativecommons.org/licenses/by/4.0/), which permits unrestricted use, distribution, and 


\section{Methods}

\section{Patients}

A total of 380 patients underwent valve replacement for rheumatic valve disease in our hospital between June 2009 and June 2017. The inclusion criteria were: mitral valve disease as the main diagnosis and rheumatic disease confirmed by pathological evaluation. The exclusion criteria were: patients with other severe cardiac diseases, such as valve disease or coronary artery disease, requiring concurrent surgical treatment. Finally, 180 patients were included in this retrospective study. The patients were divided into three groups: group A included 62 patients treated with the modified total leaflet preservation technique; group B included 80 patients treated with the posterior leaflet preservation technique; and group $\mathrm{C}$ included 38 patients treated with the no leaflet preservation technique. TEE (transoesophageal echocardiography) was performed at the end of the procedure in all patients to check for prosthesis dysfunction or left ventricular outflow tract stenosis (LVOTS).

\section{Operative methods}

All the surgeries were performed by a single surgeon. The surgeries were performed via median sternotomy under cardiopulmonary bypass (CPB), mild hypothermia, and cardioplegic arrest. Ice water was placed in the pericardial cavity after cardiac arrest. The left atrium and mitral valve were exposed through the right atrial and atrial septal incisions, respectively. The leaflets and subvalvular structures were explored carefully, and valvuloplasty was performed as a priority, if suitable. If not, MVR was considered.

Modified Total Leaflet Preservation Technique: The anterior leaflet was cut $2-3 \mathrm{~mm}$ away from the annulus.

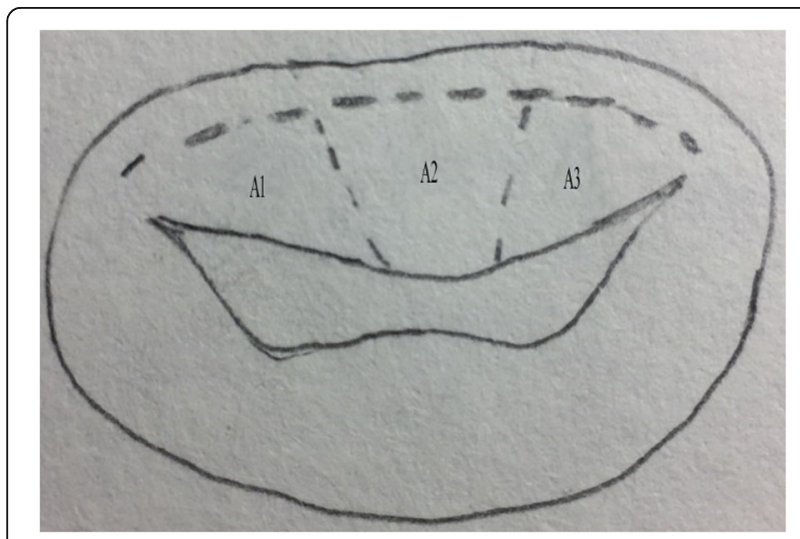

Fig. 1 Anterior leaflet resection; $A 1, A 2$, and $A 3$ are different parts of the anterior leaflet (Carpentier Type). A2 is removed while $A 1$ and $\mathrm{A} 3$ are cut and trimmed. The surgical incision is shown by the dotted line
The leaflet and subvalvular structures of A2 (Carpentier Type) were resected (Fig. 1). The leaflet and subvalvular structures of A1 and A3 were trimmed (mainly, the thickened and calcified parts were resected), and only the tissue connected to the main chordae tendineae was preserved. Finally, the preserved leaflets of A1 and A3 looked like two buttons. They were re-attached to the original MV annulus, near the anterolateral and posteromedial commissures, respectively, with 2-0 pledget-supported Ticron sutures that were taken from the atrial to the ventricular side of the leaflet and slightly away from the free margin of the annulus. The most important point was to maintain appropriate tension in the leaflet and subvalvular tissue (Fig. 2); the leaflet and subvalvular structures of P2 (Carpentier Type) were resected. The leaflet and subvalvular structures of P1 and P3 were trimmed as described for A1 and A3 (Fig. 2). The mitral annulus was measured and a suitable mechanical valve was chosen; A SORIN medical prosthesis (SORIN GROUP, Mirandola, Italy) was used in all patients. When suturing near the commissure of the annulus, the preserved parts of A1 and A3 were fixed to the prosthesis valve ring, and the preserved tissues were clamped between the mechanical valve and the original annulus (Fig. 3). The thickened and calcified parts of the leaflet were removed as much as possible, and the thickened chordae tendineae were thinned. If the chordae tendineae were thickened, fused, calcified, and shortened in a relatively severe manner, tenolysis was performed first. Subsequently, some part of the leaflet was pruned and retained so that the chordae tendineae could be replaced and its length could be extended, thereby reducing the tension of the chordae tendineae and papillary muscle. However, if the lesion of the chordae tendineae was too severe to be preserved, the chordae tendineae were replaced with an artificial substitute.

Posterior Leaflet Preservation Technique: The anterior leaflet and subvalvular tissues were removed. The posterior leaflet and subvalvular structures were preserved (calcified tissue was removed). The margin of the posterior leaflet was folded if it was too long [3].

No Leaflet Preservation Technique: Both the leaflets and subvalvular tissues were removed before MVR.

\section{Data collection and processing}

Preoperative data collected included the diagnosis, cardiac function (New York Heart Association, NYHA, grade), left ventricular end-diastolic dimension (LVEDD), left ventricular end-systolic dimension (LVESD), and left ventricular ejection fraction (LVEF). Peri-operative data on the clamp time, $\mathrm{CPB}$ time, recovery time, and early postoperative complications were also collected. LVEDD, LVESD, and LVEF were evaluated in every patient using Doppler echocardiography at the 6-month follow-up. 

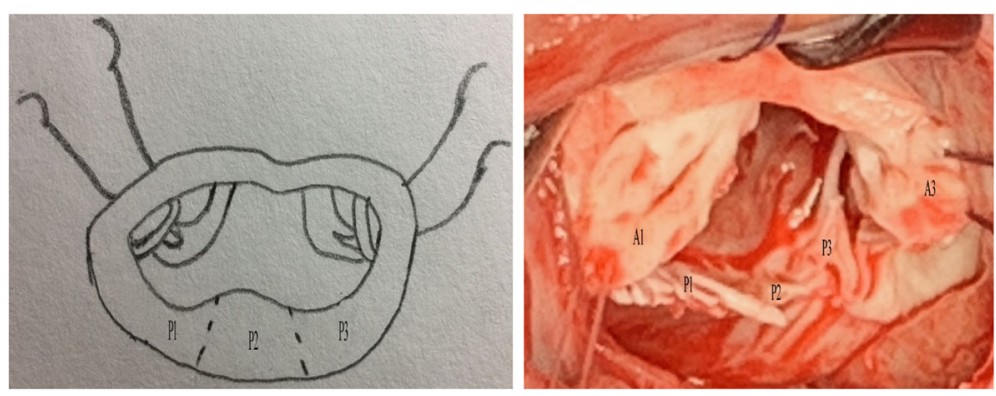

Fig. 2 Anterior leaflet re-fixation and posterior part resection. P1, P2, and P3 are different parts of the posterior leaflet (Carpentier Type). The preserved anterior leaflet (A1 and A3) is fixed to the annulus junction separately. P2 is removed. The surgical incision is shown by the dotted line

\section{Statistical analysis}

Continuous data were expressed as mean \pm standard deviation (SD) and compared using one-way analysis of variance. The least significant difference test was used for parametric variables, and the Welch and Dunnett's T3 tests were used for non-parametric variables. The chi-square test was used to compare categorical variables. All statistical data were analysed using SPSS 19.0 (IBM Inc., Armonk, NY), and $p<$ 0.05 was considered statistically significant.

\section{Results}

\section{Preoperative information}

There were no significant differences in the sex ratio, age, body surface area, major diagnosis, preoperative cardiac function (NYHA), LVEDD, LVESD, or LVEF between the three groups. The clinical profile of each group is shown in Table 1.

\section{Peri-operative data}

Intra-operative Data: The clamp time of the three groups was significantly different, in the following order: group $\mathrm{A}>$ group $\mathrm{B}>$ group $\mathrm{C}(p<0.05)$. The recovery time of the three groups was also significantly different, in the following order: group $\mathrm{A}<$ group $\mathrm{B}<$ group $\mathrm{C}(p<0.05)$. The $\mathrm{CPB}$ time of group $\mathrm{A}$ was longer than that of group $\mathrm{B}(p=0.009)$, and the $\mathrm{CPB}$ time of group $B$ was shorter than that of group $C$ $(p=0.001)$; however, there was no significant difference between the CPB times of groups A and C ( $p=$ $0.365)$. No significant difference in the prosthesis size was noted between the groups $(p=0.224)$. The pressure gradient through the prosthesis of group $C$ was lower than that of groups A and B $(p<0.01)$, but there was no significant difference in the pressure gradient through the prosthesis between group $\mathrm{A}$ and group $\mathrm{B}(p=0.656)$. The pressure gradient through the prosthesis indicated that no severe prosthesis dysfunction occurred in any of the groups (severe prosthesis dysfunction was defined as a pressure gradient of higher than $10 \mathrm{mmHg}$ through the prosthesis). The operative data are shown in Table 2.

Short-term Complications: After six months of follow-up, the operative mortality was zero, and there was no incidence of infective endocarditis or prothesis dysfunction in all the three groups. The incidence of low cardiac output syndrome (cardiac index $<2 \mathrm{~L} \cdot \mathrm{m}^{-}$ $\left.{ }^{1} \cdot \mathrm{m}^{-1}\right)$ in group A was lower than that in group $\mathrm{C}$ $(p=0.011)$. There was no left ventricular posterior wall rupture or mechanical valve dysfunction in group A. The short-term complications are shown in Table 3.
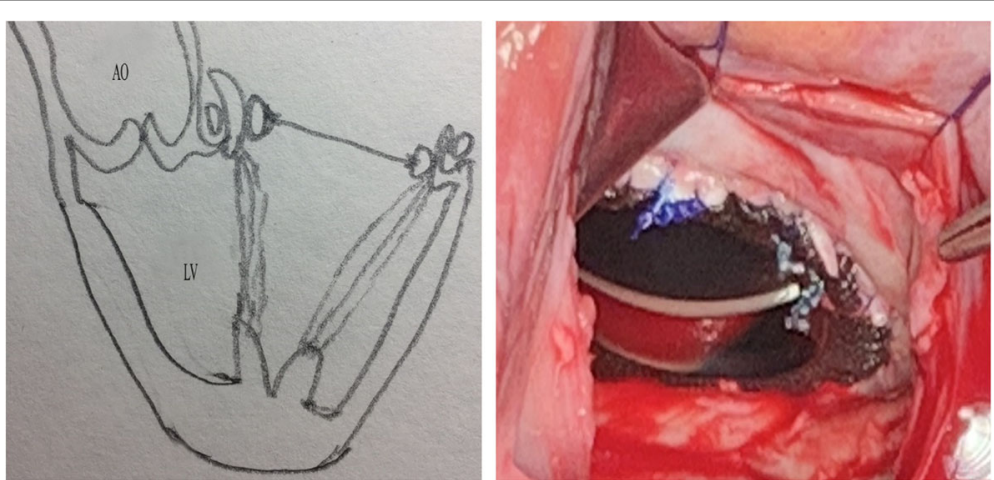

Fig. 3 The preserved tissues are placed between the mechanical valve and the original annulus. Mechanical mitral valve implantation. AO, aorta; $L V$, left ventricle 
Table 1 Clinical profiles of the three groups of patients

\begin{tabular}{|c|c|c|c|c|}
\hline & Group A $(n=62)$ & Group B $(n=80)$ & Group C $(n=38)$ & $p$ value \\
\hline Female sex & $39(63 \%)$ & $44(55 \%)$ & $22(58 \%)$ & 0.637 \\
\hline Mean age \pm SD y & $54.61 \pm 8.871$ & $52.64 \pm 8.570$ & $51.53 \pm 7.062$ & 0.168 \\
\hline Body surface area $\left(\mathrm{m}^{2}\right)$ & $1.60 \pm 0.11$ & $1.59 \pm 0.12$ & $1.56 \pm 0.12$ & 0.228 \\
\hline Diagnoses & & & & 0.637 \\
\hline MS & 28 & 32 & 12 & - \\
\hline $\mathrm{Ml}$ & 20 & 30 & 18 & - \\
\hline$M S+M l$ & 14 & 18 & 8 & - \\
\hline Heart function (NYHA) & & & & 0.779 \\
\hline$\|$ & 10 & 18 & 6 & - \\
\hline III & 40 & 46 & 24 & - \\
\hline IV & 12 & 16 & 8 & - \\
\hline LVEDD (mm) & $54.68 \pm 6.83$ & $55.58 \pm 8.57$ & $56.42 \pm 5.88$ & 0.404 \\
\hline $\operatorname{LVESD}(\mathrm{mm})$ & $45.39 \pm 3.91$ & $45.79 \pm 7.30$ & $47.21 \pm 5.53$ & 0.214 \\
\hline LVEF (\%) & $56.66 \pm 5.05$ & $56.93 \pm 4.27$ & $57.45 \pm 4.09$ & 0.700 \\
\hline
\end{tabular}

LVEDD left ventricular end-diastolic dimension, LVEF left ventricular ejection fraction, LVESD left ventricular end-systolic dimension, NYHA New York Heart Association, MI mitral valve insufficiency, MS mitral valve stenosis, MS+ MI mitral valve stenosis and mitral valve insufficiency

\section{Follow-up data}

In groups $\mathrm{A}$ and $\mathrm{B}, \mathrm{LVEDD}$ and LVESD had improved 6 months after the surgeries $(p<0.05)$. In group C, LVESD had improved $(p=0.007) 6$ months after the surgeries, while LVEDD had not $(p=0.176)$. The LVEDD, LVESD, and LVEF of group A were significantly improved at 6 months after the surgery when compared with those of the other two groups $(p<0.05)$. The echocardiography characteristics are shown in Table 4.

\section{Discussion}

The main findings of this study were: 1) the short-term effects of the modified total leaflet preservation technique were superior to those of the other techniques; 2 ) the modified technique was suitable for different types of rheumatic mitral valve disease; and 3) since there is no definite indicator to determine the appropriate tension in a clinical setting and it mainly depends on the experience of the surgeon, only experienced doctors should perform this technique.

The mitral valve is a complex and well-coordinated anatomical structure whose integrity plays a key role in maintaining normal left ventricular function. The leaflets, annulus, chordae tendineae, papillary muscle, partial left atrial wall, partial left ventricular wall, and adjacent aortic annulus are the basic structures of the mitral valve. During systole, the mitral valve and subvalvular apparatus could lead to the movement of the annulus toward the apex and the concentric contraction of the left ventricle, thereby improving the ejection function of the left ventricle $[4,5]$. Studies have demonstrated that the integrity of the mitral valve also plays a key role in maintaining right ventricular function [6]. After Lillehei et al. reported good results with the posterior leaflet preservation technique in 1964 [1], subsequent studies demonstrated that the anterior leaflet and subvalvular tissue are equally important in protecting the left ventricular function when compared to the posterior leaflet [7, 8]. Gomes conducted a study of both leaflet preservation techniques [9]. However, LVOTS is a serious complication that has restricted the development of the total leaflet preservation technique. A reduction in the left ventricular volume and excessive preservation of the anterior

Table 2 Intra-operative data of the three groups of patients

\begin{tabular}{lllll}
\hline & Group A & Group B & Group C & $p$ value \\
\hline Clamp time (min) & $56.81 \pm 4.31^{\mathrm{a}}$ & $49.19 \pm 3.33^{\mathrm{a}}$ & $39.47 \pm 3.70^{\mathrm{a}}$ & $<0.001$ \\
Recovery time (min) & $22.06 \pm 3.93^{\mathrm{a}}$ & $27.59 \pm 3.58^{\mathrm{a}}$ & $39.47 \pm 2.18^{\mathrm{a}}$ & $<0.001$ \\
CPB time (min) & $79.80 \pm 4.94^{\mathrm{a}}$ & $76.90 \pm 3.95^{\mathrm{a} . \mathrm{b}}$ & $79.74 \pm 4.62^{\mathrm{b}}$ & 0.002 \\
Prosthesis size $(\mathrm{mm})$ & $26.60 \pm 0.88$ & $26.33 \pm 1.10$ & $26.58 \pm 1.06$ & 3.224 \\
Pressure gradient $(\mathrm{mmHg})$ & $4.71 \pm 0.88^{\mathrm{a}}$ & $4.64 \pm 1.05^{\mathrm{b}}$ & $3.66 \pm 0.88^{\mathrm{a} . \mathrm{b}}$ & $<0.001$ \\
\hline
\end{tabular}

CPB time cardiopulmonary bypass time

Statistical comparisons: ${ }^{\mathrm{a}} p<0.05 ;{ }^{\mathrm{b}} p<0.01$ 
Table 3 Short-term complications in patients of the three groups

\begin{tabular}{lllll}
\hline & Group A $(n=62)$ & Group B $(n=80)$ & Group C $(n=38)$ & $p$ value \\
\hline Bleeding & 1 & 2 & 1 & 0.921 \\
Left ventricular rupture & 0 & 1 & $6^{\mathrm{a}}$ & 0.127 \\
Low cardiac output syndrome & $1^{\mathrm{a}}$ & 3 & 0 & 0.007 \\
Mechanical valve dysfunction & 0 & 1 & 8 & 0.533 \\
Pneumonia & 5 & 10 & 3 & 0.167 \\
Renal failure & 1 & 1 & 0 & 0.096 \\
Death & 0 & 0 & 0 & - \\
Infective endocarditis & 0 & 0 & & - \\
\hline
\end{tabular}

Low cardiac output syndrome was defines as cardiac index less than $2 \mathrm{~L} \cdot \mathrm{min}^{-1} \cdot \mathrm{m}^{-1}$

Statistical comparison: ${ }^{a} p<0.05$

leaflet and subvalvular tissue are the main reasons for LVOTS [10, 11].

Alsaddique's total leaflet preservation technique had two major drawbacks. One, the preserved tissue was extensive because it was restored to the annulus after the leaflet was cut from the centre and trimmed properly, and two, the technique only applied to patients with mitral regurgitation [2]. Compared to the traditional technique, the modified technique has two major improvements. One, the leaflet and subvalvular tissues of A2 and P2 were resected and the other part was trimmed appropriately, resulting in reduction of the preserved tissues. Only the tissues connected to the main chordae tendineae were preserved in a button-like manner and fixed at the junction of the annulus. Two, the modified technique is also considered suitable for rheumatic mitral stenosis.

Our modified technique resulted in the following major results: 1) the incidence of low cardiac output syndrome was reduced; 2) LVEDD, LVESD, and LVEF were significantly improved postoperatively; and 3) the modified technique was more complicated and the clamp time was longer; therefore, myocardial ischaemic time was increased. However, the recovery time was shorter. The recovery time is an important index for resuscitation effects; therefore, the resuscitation effects were better in group A.

In our experience, the following points should be focused on when applying this modified technique. One, the anterior leaflet and subvalvular tissue must be managed carefully. Excessively preserved tissues might protrude into the left ventricular outflow tract and lead to LVOTS [11]. Therefore, the leaflet of the A2 area was resected routinely and the remaining tissue connected to the main chordae tendineae was trimmed and preserved in a "button-like" manner. Subsequently, the preserved tissue of the anterior leaflet was transferred and fixed at the junction of the annulus. The chordae tendineae and papillary muscles were kept in a suitable tension. This was beneficial not only for preserving the integrity of the mitral valve but also for protecting left ventricular function $[9,12]$. Two, the preserved tissue must be placed between the mechanical valve and the original annulus to reduce its effects on the mechanical valve [3]. Three, only the main chordae tendineae were preserved. If the lesion of the chordae tendineae was too severe to be preserved, the chordae tendineae could be replaced with an artificial substitute [13]. MVR with leaflet preservation technique may result in patient-valve mismatch, especially in female patients with severe mitral valve stenosis [14]. The preserved valve and subvalvular apparatus should be trimmed to the greatest extent. If a suitable valve still cannot be implanted, then the total leaflet preservation technique should be abandoned, and the posterior leaflet preservation technique or the no valve preservation technique should be applied.

This study has some limitations. This was a retrospective, non-randomised study with no multivariate analysis performed; therefore, a certain selection bias exists. Further prospective, randomised, large-scale, long-term studies with

Table 4 Echocardiography characteristics of the patients of the three groups

\begin{tabular}{|c|c|c|c|c|c|c|}
\hline & \multicolumn{2}{|l|}{ LVEDD (mm) } & \multicolumn{2}{|l|}{ LVESD (mm) } & \multicolumn{2}{|l|}{ LVEF (\%) } \\
\hline & Preoperative & $\overline{\text { Postoperative }}$ & Preoperative & Postoperative & Preoperative & Postoperative \\
\hline Group A & $54.68 \pm 6.83$ & $50.10 \pm 2.86^{a}$ & $45.39 \pm 3.91$ & $38.74 \pm 2.50^{a}$ & $56.66 \pm 5.05$ & $57.92 \pm 1.99^{a . b}$ \\
\hline Group B & $55.58 \pm 8.57$ & $51.66 \pm 2.84^{\mathrm{a}}$ & $45.79 \pm 7.30$ & $41.05 \pm 4.90^{\mathrm{a}}$ & $56.93 \pm 4.27$ & $56.76 \pm 2.24^{b}$ \\
\hline Group C & $56.42 \pm 5.88$ & $55.03 \pm 2.24^{\mathrm{a}}$ & $47.21 \pm 5.53$ & $44.45 \pm 2.63^{a}$ & $57.45 \pm 4.09$ & $55.55 \pm 2.39^{a}$ \\
\hline$p$ value & 0.404 & $<0.001$ & 0.214 & $<0.001$ & 0.700 & $<0.001$ \\
\hline
\end{tabular}

LVEDD left ventricular end-diastolic dimension, LVEF left ventricular ejection fraction, LVESD left ventricular end-systolic dimension

Statistic comparisons: comparison between groups, ${ }^{a} p<0.01$; ${ }^{\mathrm{b}} p<0.05$ 
multivariate analysis are required to validate our findings. Moreover, there was a larger number of patients with mitral regurgitation in group C. This could justify the slight decrease of LVEF in this group, so more attention should be paid to this issue in future studies.

\section{Conclusions}

In conclusion, the short-term results of the modified total leaflet preservation technique were better than those of the other techniques. This modified technique is also suitable for patients with rheumatic mitral valve stenosis.

\section{Abbreviations}

CPB: Cardiopulmonary bypass; LVEDD: Left ventricular end-diastolic dimension; LVEF: Left ventricular ejection fraction; LVESD: Left ventricular endsystolic dimension; LVOTS: Left ventricular outflow tract stenosis; MI: Mitral valve insufficiency; MS: Mitral valve stenosis; MVR: Mitral valve replacement; NYHA: New York Heart Association; SD: Standard deviation;

TEE: Transoesophageal echocardiography

\section{Acknowledgements}

Not applicable.

\section{Funding}

This work was supported by a grant from 2018 Hainan Provincial Natural Science Foundation for Youth (grant number: 818QN319).

\section{Availability of data and materials}

All data generated or analysed during this study are included in this published article and the supplementary information files.

\section{Authors' contributions}

YG designed the study and drafted the manuscript. YS carried out the administrative support. SH carried out the provisions of the study patients. TW participated in the collection and assembly of data. ZC participated in the data analysis and interpretation. All authors have read and approved the final manuscript.

\section{Ethics approval and consent to participate}

This study was approved by the Hainan Medical University Clinic Institutional Review board, and the need for patient consent was waived due to the retrospective study design.

\section{Consent for publication}

Not applicable.

\section{Competing interests}

The authors declare that they have no competing interests.

\section{Publisher's Note}

Springer Nature remains neutral with regard to jurisdictional claims in published maps and institutional affiliations.

Received: 25 January 2019 Accepted: 13 May 2019

Published online: 07 June 2019

\section{References}

1. Lillehei CW, Levy MJ, Bonnabeau RC Jr. Mitral valve replacement with preservation of papillary muscles and chordae tendineae. J Thorac Cardiovasc Surg. 1964;47:532-43.

2. Alsaddique AA. Mitral valve replacement with the preservation of the entire valve apparatus. Rev Bras Cir Cardiovasc. 2007;22:218-23.

3. Kirali K, Tuncer A, Uyar I, Mansuroğlu D, Dăglar B, lpek G, et al. Is posterior leaflet preservation in the surgical treatment of rheumatic mitral insufficiency without left ventricular dysfunction necessary? Cardiovasc Surg. 2001;9:58-63.
4. Coutinho GF, Bihun V, Correia PE, Antunes PE, Antunes MJ. Preservation of the subvalvular apparatus during mitral valve replacement of rheumatic valves does not affect long-term survival. Eur J Cardiothorac Surg. 2015;48: 861-7 discussion 867.

5. Gunnal SA, Wabale RN, Farooqui MS. Morphological study of chordae tendinae in human cadaveric hearts. Heart Views. 2015;16(1):12.

6. Kessel SM, Hawkins RB, Yarboro LT, Ailawadi G. Total chordal sparing mitral valve replacement in rheumatic disease: a word of caution. Ann Thorac Surg. 2017;104:e47-8.

7. Ozdemir AC, Emrecan B, Baltalarli A. Bileaflet versus posterior-leaflet-only preservation in mitral valve replacement. Tex Heart Inst J. 2014:41:165-9.

8. Chen L, Chen B, Hao J, Wang X, Ma R, Cheng W, et al. Complete preservation of the mitral valve apparatus during mitral valve replacement for rheumatic mitral regurgitation in patients with an enlarged left ventricular chamber. Heart Surg Forum. 2013;16:E137-43.

9. Gomes OM, Gomes ES, Santana Filho GP. New technical approach for crossed papillopexy in mitral valve replacement surgery: short term results. Braz J Cardiovasc Surg. 2005;20:340-5

10. Kalcik M, Yesin M, Gunduz S, Gürsoy MO, Bayam E, Özkan M. Left ventricular side obstructive pannus formation after rheumatic mitral valve replacement with preservation of the subvalvular apparatus. Echocardiography. 2015;32:1887-8.

11. Patel H, Antoine SM, Funk M, Santana O. Left ventricular outflow tract obstruction after bioprosthetic mitral valve replacement with preservation of the anterior leaflet. Rev Cardiovasc Med. 2011;12:48-51.

12. Lafci G, Cagli K, Cicek OF, Korkmaz K, Turak O, Uzun A, et al. Papillary muscle repositioning as a subvalvular apparatus preservation technique in mitral stenosis patients with normal left ventricular systolic function. Tex Heart Inst J. 2014;41:33-9.

13. Soga Y, Nishimura K, Yamazaki K, Komeda M. Simplified chordal reconstruction: 'oblique' placement of artificial chordae tendineae in mitral valve replacement. Eur J Cardiothorac Surg. 2003;24:653-5.

14. Zakai SB, Khan SUR, Rabbi F, Tasneem H. Effects of mitral valve replacement with and without chordal preservation on cardiac function: early and midterm results. J Ayub Med Coll Abbottabad. 2010;22:91-6.

\section{Ready to submit your research? Choose BMC and benefit from:}

- fast, convenient online submission

- thorough peer review by experienced researchers in your field

- rapid publication on acceptance

- support for research data, including large and complex data types

- gold Open Access which fosters wider collaboration and increased citations

- maximum visibility for your research: over $100 \mathrm{M}$ website views per year

At BMC, research is always in progress.

Learn more biomedcentral.com/submissions 